\title{
BICYCLE PATH STUDY FOR \\ GLACIER NATIONAL PARK, MONTANA
}

Eugene Wilson

Department of Civil Engineering
Donald Warder

Department of Recreation and Park Administration

$$
\text { University of Wyoming }
$$

This preliminary report is intended only to provide a brief scenario of the project to date. As information pertaining to possible mitigating influences is still pending, we are unable to present a completed project at this time.

\section{Purpose and Objectives}

The principal focus of our study was to evaluate alternative bicycle paths which would be consistent with the Glacier National Park Master Plan.

In addition, the following specific objectives provided guidance to the study:

1. To evaluate the scale of development and investment for bicycle facilities.

2. To evaluate potential bicycle usage, considering the following: esthetics of the proposed facility, impact on wildlife, required bicycle performance criteria, potential bicycle demand, and the safety of present facilities.

\section{Methods}

Each road within and adjacent to the Park was evaluated on the basis of its general suitability for safe bicycle travel. In order to provide some type of guidance for this road survey, the bicycle user was categorized into two groups: 1) the local user, and 2) the through user. After completing the on-site evaluations of the various roadways, attention was turned to alternative routes.

Two principal alternative routes, through and within the park, were considered. The first being along the west side of Lake McDonald, and the second along the abandoned telephone right-of-way east of Lake McDonald. The existing trail system for both of these areas was observed and noted. Certain factors regarding locating the paths in these areas were considered and use of the abandoned telephone right-of-way was recommended.

In addition to these on-site evaluations interviews with the Park staff and with bicycle users of the Park were conducted.

The approach for each set of interviews followed the methodology commonly known as the ethnographic approach. Individuals were interviewed, issues 
pertaining to the study were discussed, but no response was pressured. Through this approach, the attempt was to modify the question sets on the basis of the previous interview. At a point where the researcher was able to accurately predict what the next respondent would say, the interviews stopped. Data from these interviews is still being digested and prepared. The final report will have the results.

One last technique was employed in the on-site process. The primary road systems and alternatives were filmed for later follow-up for the purpose of making specific reference to locations when discussing the units under consideration.

Preliminary Conclusions

The final bicycle plan to be developed will emphasize the need to improve safety for the Park user. A limited system plan will be developed which will focus on the major activity centers within the Park. In addition, alternative bicycle facilities and policies will be proposed for the major travel route from West Glacier to St. Mary. The alternatives to be developed will be prioritized and design alternatives suggested. The original Park proposal, included in the Master Plan, suggested a bicycle facility along the west side of Lake McDonald. This was evaluated, and this study will recommend that this proposed facility not be built. 